\title{
Aestivation in Pieris brassicae (Lepidoptera: Pieridae): Implications for parasitism
}

\author{
Hubert R. SPIETH AND ELKe SCHWARZER \\ Faculty of Biology, Department of Animal Ecology, University of Bielefeld, Morgenbreede 45, D-33615 Bielefeld, Germany \\ e-mail: Hubert.Spieth@biologie.uni-bielefeld.de
}

Key words. Pieris brassicae, Cotesia glomerata, Braconidae, photoperiodic response, aestivation, migration, parasitism, Iberian peninsula

\begin{abstract}
Only in the southern part of the Iberian Peninsula the large white butterfly Pieris brassicae was recorded to pass the summer in pupal aestivation, induced by long-day photoperiods. It is not clear why this photoperiodic response is regionally restricted. We investigated whether the change of life history in $P$. brassicae may affect the infestation by parasites. This was done by testing the coincidence of photoperiodic responses in both the host P. brassicae and in its main parasitoid Cotesia glomerata. While the response under short-day conditions was very similar in both species, no summer dormancy of any type was found in the parasitoid at photophases $\geq 15 \mathrm{~h}$ and temperatures of $15^{\circ}-25^{\circ} \mathrm{C}$ in contrast to $100 \%$ aestivation in the host. We suggest that aestivation is a response which allows the host to desynchronise its life cycle from that of its parasitoid. This is effective because parasitoid wasps cannot pass the temporary absence of suitable host stages by a similar developmental rest. C. glomerata is then forced to switch to less adequate host species which diminishes its reproductive success.
\end{abstract}

\section{INTRODUCTION}

The photoperiodic response of the large white butterfly, $P$. brassicae L., has been known as a typical long-day type (Beck, 1980), i.e. long photophases induce a nondiapause response (Danilevskij, 1965; Spieth, 1985). Recently, a locally restricted population has been found in southern Spain which surprisingly exhibits another response type showing a dormancy under long photophases as well (Held \& Spieth, 1999). This short-day/long-day response type (Beck, 1980) undergoes two developmental rests, a winter dormancy (= hibernation diapause) and a summer dormancy (= aestivation diapause). Together with a local Chinese population of the widespread Pieris melete (Xue et al., 1997), P. brassicae is the second species of the large Pierid family known to aestivate.

The reason for this newly revealed behaviour is unclear because aestivation in $P$. brassicae is restricted to Iberian populations (Fig. 1) whereas individuals from nearby Southern France (Held \& Spieth, 1999) or Southern Italy (Spieth, unpublished data) develop in a continuous sequence of generations from early spring to late autumn, often coupled with a migration to regions with less adverse climate, as in Israel (Benyamini, 1996) or India (Williams, 1958). There must be a strong selective pressure on the conservation of this behaviour (Held \& Spieth, 1999) because all individuals from the tested Iberian populations endure the summer months in a stage of aestivation.

Generally aestivation has been regarded as an adaptation to survive unfavourable climatic conditions like drought and heat (Beck, 1980; Oku, 1983; Grüner \& Masaki, 1994; Nakai \& Takeda, 1995). Other authors have emphasised that aestivation is a response to a dimin- ished availability and quality of larval food plants due to summer drought (Masetti \& Scali, 1972; Masaki, 1961, 1980; Grüner \& Sauer, 1988; Nagasaka, 1992; Braby, 1995; Košt'ál \& Hodek, 1997). Therefore, food supply has been regarded as the fundamental factor for the evolution of aestivation. Furthermore, aestivation may have a synchronising effect on the autumnal activity of polyvoltine insects (Košt'ál \& Hodek, 1997), or may be a tuning mechanism to expose the photosensitive phase of a generation to autumnal short-days inducing a hibernation diapause at the right season (Wiklund et al., 1983; Nylin et al., 1989; Gomi, 1997; Takeda, 1997). Masaki (1980) has also named predation by summer breeding birds to be a selective force for the evolution of aestivation in potential prey species. However, neither of these mechanisms actually explain the geographical pattern of the response in P. brassicae.

In this paper we investigate whether parasitism may effect the evolution of aestivation. $P$. brassicae is attacked by many hymenopterous parasitoids. From all known species, no matter if we compare egg, larval, or pupal parasitoids, the most successful is Cotesia glomerata (Hymenoptera: Braconidae) which can regionally inflict $100 \%$ losses of larvae (Feltwell, 1982). Assuming that aestivation in the large white butterfly may cause the strongest effect on its main parasitoid we tested whether C. glomerata from the Iberian Peninsula is co-adapted to its hosts summer rest and aestivates as well.

\section{MATERIAL AND METHODS}

\section{Life history of Cotesia glomerata}

First and second instars of $P$. brassicae are the most suitable stages to be attacked by $C$. glomerata. Older larvae possess defence reactions like spitting and biting. C. glomerata females inject 20-21 eggs on average into host larvae (Le Masurier, 


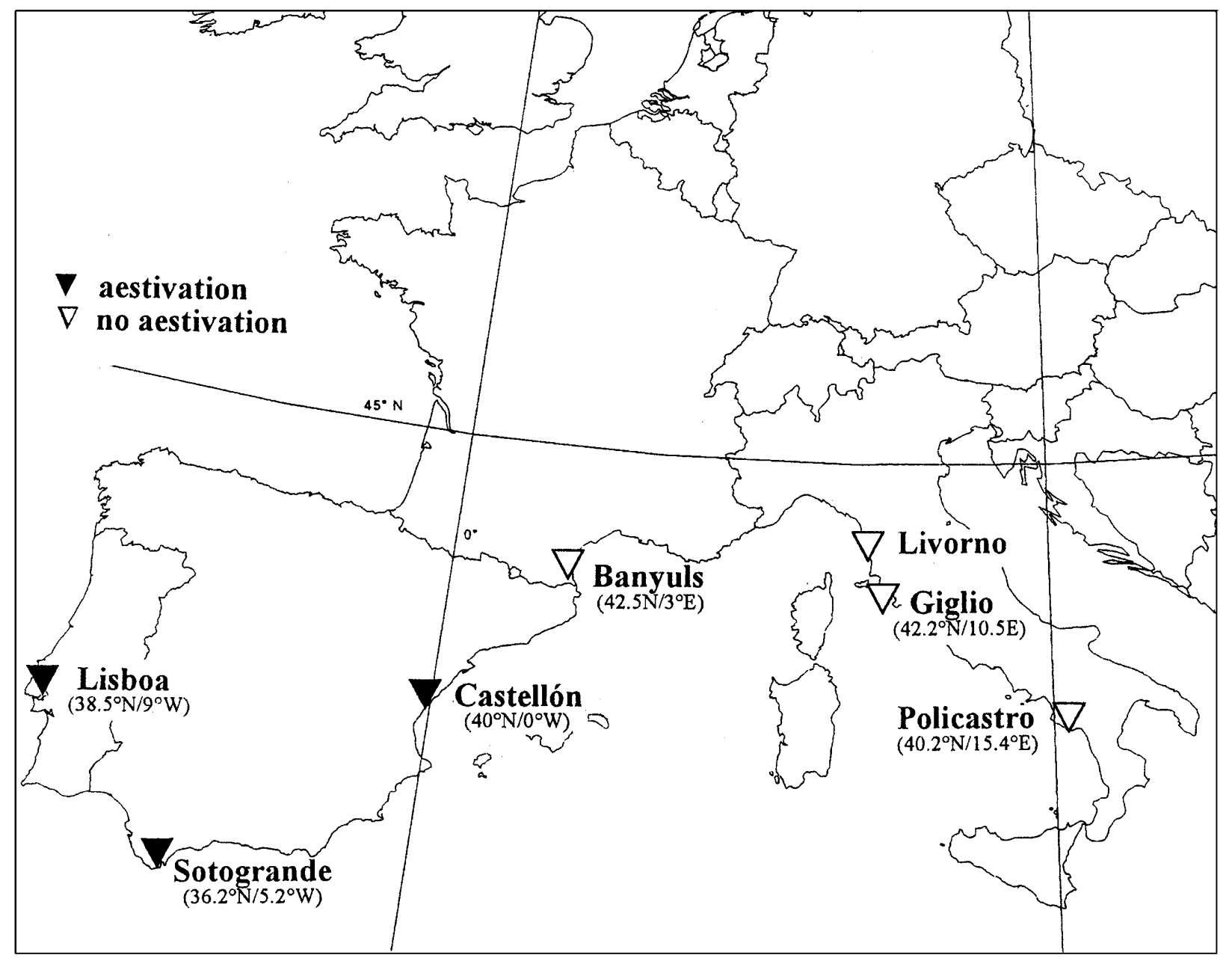

Fig. 1. Map of the collection sites of Pieris brassicae eggs and caterpillars which were tested for their aestivation response in our laboratory.

1991). One host larva can be parasitised by more than one female which results in superparasitism. Immature parasitoids undergo three larval instars. The first moulting is finished inside the third or fourth instar stage of $P$. brassicae. Larvae moult to the third instar during emergence out of the host's body (Hamilton, 1936; Sato, 1980). By this time the parasitised caterpillar has reached the fifth and last instar. Immediately after emergence the larvae of $C$. glomerata spin cocoons on the remnants of their abandoned host forming a cluster of cocoons.

C. glomerata shows a facultative diapause response depending on the photoperiod. The diapause stage is the prepupa (Geispits \& Kyao, 1953; Wilbert, 1959; Danilevskij, 1965). The developmental pathway, diapause or non-diapause, is induced independently from the host's mode of development (Geispits \& Kyao, 1953; Maslennikova, 1959).

\section{Rearing conditions of Cotesia glomerata}

Parasitised larvae of $P$. brassicae were collected in the vicinity of Lisboa, Portugal $\left(38^{\circ} 45^{\prime} \mathrm{N}, 9^{\circ} 15^{\prime} \mathrm{W}\right)$, May 1997 . Each cocoon cluster of parasitoids derived from a single caterpillar was kept in a plastic jar on a piece of tissue paper at $21^{\circ} \mathrm{C}$, with a photoperiod of $16 \mathrm{~L}: 8 \mathrm{D}$. Under these conditions eclosion of adults starts after 7 to $8 \mathrm{~d}$. Thereafter they were identified according to Nixon (1974) and Medvedev (1995). Wasps were held in a plastic jar and fed honey water solution with fresh inflorescences of Apiaceae. Moistened tissue paper produced sufficient humidity. Mating starts soon after eclosion. We did not separate mated and unmated females. To enhance the certainty of successful attacks by the parasitoids we used 5 to 8 females and offered them a batch of 15-30 first or second instar caterpillars for parasitism. After $1 \mathrm{~h}$ the females were removed. During that period all cases from no attack to many attacks by several females occur. Thus, we obtained a batch of caterpillars from each jar normally attacked by more than one parasitoid, i.e. superparasitised larvae in most cases.

After that procedure, cocoons were randomly assigned to one of the groups reared under a constant photoperiod between 10L: $14 \mathrm{D}$ and $16 \mathrm{~L}: 8 \mathrm{D}$, respectively, at constant temperatures of $21^{\circ} \mathrm{C}$ or $15^{\circ} \mathrm{C}$ and $\sim 50 \%$ relative humidity. Technical equipment and feeding conditions of the caterpillars were the same as for unparasitised Pieris larvae (see below). After cocoon clusters had been formed each cluster was placed in a separate plastic jar preserved in the same condition as the caterpillars before.

\section{Rearing conditions of the host larvae}

With the unparasitised specimens from Lisboa a laboratory strain was established. Ten pairs of butterflies were held in cages $(0.5 \mathrm{~m} \times 0.5 \mathrm{~m} \times 1.0 \mathrm{~m})$ to lay eggs on leaves of Brassica oleracea. Egg clusters with up to 150 eggs were kept on moist tissue paper in petri dishes under $10 \mathrm{~L}: 14 \mathrm{D}$ and $21^{\circ} \mathrm{C}$ in an incubator. With these conditions, larvae emerged after 5 to $6 \mathrm{~d}$. The hatched larvae were randomly assigned to one of three groups: one for parasitism in the first or second stage, another 


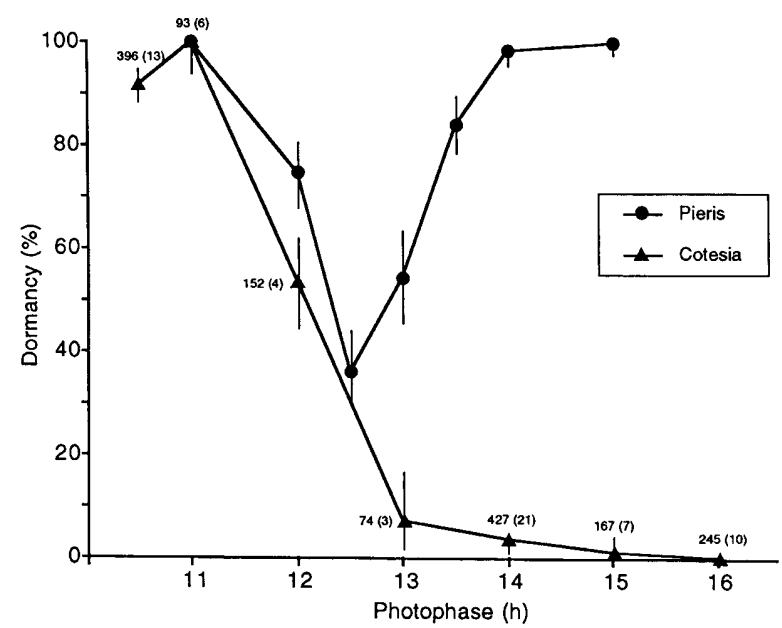

Fig. 2. Photoperiodic response of Cotesia glomerata and its host Pieris brassicae at $15^{\circ} \mathrm{C}$. For Cotesia the number of cocoons and clusters (in parentheses) is noted for each curve point. Error bars indicate the $95 \%$ confidence interval based on cocoon eclosion.

for continuous rearing of a laboratory stock, and a third to test the photoperiodic response of $P$. brassicae. Larvae of the first and second group were reared in incubators under $21^{\circ} \mathrm{C}$ and $16 \mathrm{~h}$ of light, respectively. The third group was held under $\mathrm{L} / \mathrm{D}$ regimes of $10 / 14 \mathrm{~h}$ to $16 / 8 \mathrm{~h}$ at constant temperatures of $21^{\circ} \mathrm{C}$ or $15^{\circ} \mathrm{C}$. Up to 30 larvae were placed in a plastic box $(10 \times 10 \times 7$ $\mathrm{cm})$ with a gauze lid and moistened tissue paper at the bottom. Once a day, boxes were cleaned and larvae were fed fresh leaves of Brassica oleracea botrytis or B. oleracea medullosa. Food plants were not changed during the experiment.

\section{Determination of diapause incidence}

Cocoons of the parasitoid were dissected to determine the incidence of diapause. This is essential as intact cocoons can bear not only diapausing prepupae but also dead larvae, developing pupae, or dead adults which had not been able to open the cocoon. Dissection took place $16 \mathrm{~d}$ after cocoon formation at $21^{\circ} \mathrm{C}$ and after $28 \mathrm{~d}$ at $15^{\circ} \mathrm{C}$. Developing pupae were

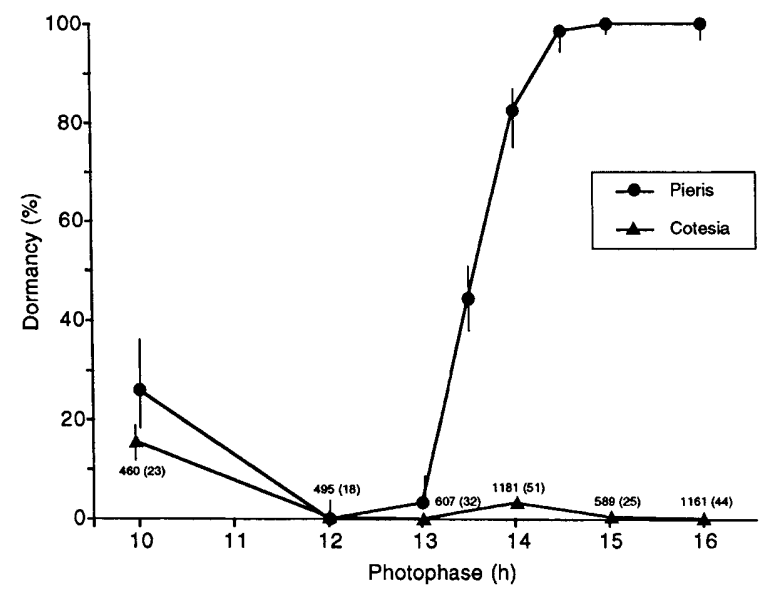

Fig. 3. Photoperiodic response of Cotesia glomerata and its host Pieris brassicae at $21^{\circ} \mathrm{C}$. For Cotesia the number of cocoons and clusters (in parentheses) is noted for each curve point. Error bars indicate the $95 \%$ confidence interval based on cocoon eclosion. scarcely found after that period. Dissected cocoons were grouped as follows:

a) Only living prepupae without pigmented ocelli and compound eyes were counted as diapausing.

b) Pupae and adults, either living or dead, were counted as nondiapausing.

c) Dead larvae were ignored as they cannot be detected as a diapause or non-diapause instar.

After wasp eclosion no delay of adult maturity was detected under the respective conditions.

\section{RESULTS}

To show whether a summer diapause could be induced in $C$. glomerata, parasitised larvae of $P$. brassicae were reared at $15^{\circ} \mathrm{C}$ and photophases between $10 \mathrm{~h}$ and $16 \mathrm{~h}$. Cocoons were kept under rearing conditions. The photoperiodic response is presented in Fig. 2. For comparison the response of unparasitised $P$. brassicae from Lisboa under the same rearing conditions is shown as well.

Under relatively short photophases of $10: 30 \mathrm{~h}$ to $11 \mathrm{~h}$ of light $92 \%$ to $100 \%$ of the parasitoids respond with dormancy. Under relatively long photophases ( $>14 \mathrm{~h}$ ) no developmental rest occurs. This photoperiodic response is of a typical long-day type, adaptive for hibernation diapause (Beck, 1980).

In comparison, the incidence of dormancy in $P$. brassicae was $100 \%$ at $11 \mathrm{~h}$ of light and decreases to $36 \%$ at $12.30 \mathrm{~h}$ but increases again up to $100 \%$ at $14 \mathrm{~h}$. The typical hibernation diapause response of the host species between $11 \mathrm{~h}$ and $12.30 \mathrm{~h}$ of light switched to an aestivation response under longer day lengths. In contrast, $C$. glomerata shows no aestivation under these photoperiodic regimes.

The same experiment was carried out at a temperature of $21^{\circ} \mathrm{C}$. The photoperiodic response of both C. glomerata and its host $P$. brassicae is outlined in Fig. 3 . The curves parallel each other in the shorter day lengths between 10 and $12 \mathrm{~h}$. Dormancy decreases to $0 \%$ at $12 \mathrm{~h}$ of light. Both species show a weak response to short day lengths only, which means that no hibernation diapause was induced in most individuals at $21^{\circ} \mathrm{C}$. However, the photoperiodic response differs entirely between 12 and 16 h. In $P$. brassicae the aestivation incidence increases with increasing photophases up to $100 \%$ at a day length of $>$ $14 \mathrm{~h}$. In contrast, the dormancy of $C$. glomerata remains at $0 \%$, thus no aestivation was induced in the parasitoid at this higher temperature either. The weak response at $14 \mathrm{~h}$ $(3 \%)$ is due to descendants of one cocoon cluster out of 51 clusters.

To make sure that an aestivation response of the parasitoid does not occur at high summer temperatures, a control experiment at a constant mean temperature of $25^{\circ} \mathrm{C}$ and $16 \mathrm{~h}$ of light was carried out. From 220 cocoons out of 9 cocoon clusters, none of the parasitoids respond with a developmental delay; i.e. no aestivation was detectable.

\section{DISCUSSION}

The braconid C. glomerata is the principal parasitoid of the large white butterfly, $P$. brassicae. Its distribution corresponds largely with that of its host species. In the 
southern regions of the Iberian Peninsula the host butterfly aestivates from end of May to about end of August (Held \& Spieth, 1999). We did not found an adequate response in any developmental stage of the parasitoid to the summer rest of the host, even no delay of maturity. There was no incidence of aestivation under temperature regimes of 15 to $25^{\circ} \mathrm{C}$ and photophases even longer than the natural day length. A developmental rest in one of the co-adapted species leads to a desynchronisation of their life cycles. We assume that this is an advantage for the post-aestivation generation of $P$. brassicae, which might be less infested by its principal parasitoid.

This hypothesis assumes that $C$. glomerata suffers a breakdown in population density. Therefore, the most important question is how does C. glomerata behave during the aestivation period of its principal host? Moiseeva (1960) estimates the longevity of adult wasps up to $30 \mathrm{~d}$. The aestivation period of $P$. brassicae lasts about three months and thus cannot be bridged by one generation of parasitoids. Thus, C. glomerata is restricted to attacking caterpillars of other butterflies (Wiskerke \& Vet, 1994; Brodeur \& Vet, 1995), especially the closely related pierids Pieris rapae and Pieris napi and less frequently the larvae of the apple pierid Aporia crataegi (Maslennikova, 1958; Wilbert, 1959; Lien-Chang, 1965).

Among these possible hosts $P$. brassicae is referred to as the main host species (Laing \& Levin, 1982; Dempster, 1984). C. glomerata shows higher acceptance of P. brassicae than of $P$. rapae and $P$. napi (Brodeur et al., 1996). In addition, $P$. rapae and $P$. napi show quite a different egg laying pattern compared to $P$. brassicae. They normally lay only a single egg per plant, whereas the large white butterfly lays clusters of up to 150 eggs (own observations). When a cluster of $P$. brassicae is discovered by a wasp a great number of caterpillars can be parasitised at once, whereas many food plants have to be searched to find the same number of single living larvae. C. glomerata shows no difference in the propensity to search for $P$. brassicae or $P$. rapae but is more adapted to foraging for gregariously feeding hosts (Wiskerke \& Vet, 1994). Further disadvantages for C. glomerata are the facts that $P$. rapae is the main host of Cotesia rubecula, a specialist solitary parasitoid, which is superior to C. glomerata when both species occur in the same larva (Richards, 1940), and that encapsulation of C. glomerata eggs is more effective by $P$. rapae (Brodeur \& Vet, 1995 ). Enduring the aestivation of $P$. brassicae by parasitising the alternative host therefore reduces reproductive success of $C$. glomerata. The same applies to endurance in $P$. napi. In contrast to $C$. glomerata, this potential host species prefers shady and moist habitats and is rarely found on cabbage (Feltwell, 1982; Sato \& Ohsaki, 1987). Furthermore, Brodeur et al. (1998) showed that the survival rate and the size of $C$. glomerata developing in $P$. brassicae were higher than those developing in $P$. napi.

Aporia crataegi as a host has a quite different life cycle than $P$. brassicae. It is a univoltine species which does not develop in the same year to the fully grown fifth instar, but diapauses in the relatively small third stage. $C$. glomerata normally exploits the fully grown caterpillar and only leaves the last instar to pupate. Furthermore, the caterpillars of $A$. crataegi only use Rosaceae as host plants. The wasp has to locate its prey by different chemical clues as all the other hosts feed on Brassicacea and females of C. glomerata are normally attracted to the volatile mustard oils of this plant family. Though $A$. crataegi is present in July (Gómez-Bustillo \& FernandezRubio, 1974), when $P$. brassicae aestivates for some months, it is not an adequate alternative host for C. glomerata.

Summarising these arguments, it can be concluded that C. glomerata switches to alternative hosts during the aestivation of its main host but suffers a fitness reduction due to the drastically reduced number of caterpillars, the better developed immune defence of other hosts, the adjustment in searching for single larvae or host plants with other volatiles, and the competition with other host specific parasitoids. Therefore, a strong reduction of the population densities of $C$. glomerata can be expected. This in turn should be positive for the post-aestivation generation of $P$. brassicae in late August/early September. Corresponding field studies to check this statement are planned.

A further point concerns the role of parasitism for the evolution of aestivation in $P$. brassicae. We do not claim parasitism to be the primary selective factor decisive for this response. It cannot be excluded that aestivation has evolved for other reasons and minimising the parasitism rate may only be an unselected effect. Limitations of food supply caused by climate and weather are the most quoted reasons for the evolution of aestivation in insects (see introduction). In our case it also seems to be an obvious argument as all localities of the tested populations are found within the Mediterranean climatic zone with its characteristic dry season in the summer. During the time of low precipitation from June to August the daily average temperatures in Lisboa are $20^{\circ} \mathrm{C}-23^{\circ} \mathrm{C}$ and in Castellõn und Policastro $22^{\circ} \mathrm{C}-25^{\circ} \mathrm{C}$. The major part of rain falls from September to May (Walter \& Lieth, 1960; Müller, 1983). In the Policastro region precipitation (approx. $870 \mathrm{~mm}$ ) is about twice as high as in the very dry region around Castellõn. Thus the dry season in Policastro shortens to about 2.5 months. However, this does not alter the fact that the vegetation suffers under water stress and most forage plants dry up. Until the evidence of aestivation in Spain it was assumed that P. brassicae has two options to pass this dry seasons without a developmental rest. First, its caterpillars live frequently on dry resistent plants as the circummediterranen Capparis spinosa (Benyamini, 1996) or Cacile maritima and of course on cultivated Brassica oleracea ssp.. Secondly, the adults have the potential to escape pessimal conditions by migration (Williams, 1958). This was recently confirmed by Jamda (1991) in India. The environmental context in which one of the both tactics is used by the species is not investigated. In Spain the large white shows similar behavioural patterns. It uses the same range of forage plants (Diego Jordano, pers. com.) and migration is also 
reported (Gómez Bustillo \& Fernández-Rubio, 1974). With this, the question of the benefit of the local aestivation in this system, compared to the other possibilities, is still unanswered.

These circumstances led us to look for hypotheses regarding the adaptive value of aestivation. We have only made a little progress. Parasitization per se need not lead to the evolution of aestivation but it might under certain ecological conditions. We try to explain in a most parsimonious way why aestivation in $P$. brassicae, that evolved in Southern Spain, remained geographically limited. We suppose that it cannot disperse into climatically milder areas of the Mediterranean region because of the cost in respect to voltinism. We did not record aestivation at the Mediterranean coast of Southern France during many years of study and assume that it is not adaptive in the northern Mediterranean region. Aestivation for three to four months, like in Southern Spain, costs 3 generations, because the generation time of $P$. brassicae in summer is less than 30 days. Despite the loss of 3 generations the species produces there 5 generations (Held \& Spieth, 1999), or even 6 generations (unpubl.). In Southern France (Fig. 1; Banyuls) we did not find more than 5 generations per year, in spite of continuous succession. Under these circumstances aestivation would result in a change of the life history from a polyvoltine to a bivoltine life cycle.

We expect further costs resulting from a higher mortality during the immobile pupal stage, which is prolonged by at least ten times compared to a life cycle without dormancy. Thus, the time increases during which summer active predators (above all birds and arthropods) and parasites can attack the pupae. With next experiments we shall examine whether the cost of the aestivation exceeds the benefit of this behaviour in populations with less than 5 generations. This would explain why aestivation does not occure in the northern Mediterranean region. We expect that the parasitization will be of essential importance for this cost/benefit analysis.

ACKNOWLEDGEMENTS. We express sincere thanks to Martin Renner for valuable comments and suggestions on the manuscript. We are also indebted to Chris Thomas and Ivo Hodek for their criticism on an earlier version. We would never have received the animals from southern Spain in time without the selfless help of Christiane Werner and Uli Mok.

\section{REFERENCES}

BECK S.D. 1980: Insect Photoperiodism. Academic Press, New York, $387 \mathrm{pp}$.

Benyamini D. 1996: Pupal summer diapause in Chilean Pieris brassicae (Linnaeus, 1758) (Lepidoptera, Pieridae). Nota Lepidopterol. 18: 184-192.

BRABY M.F. 1995: Reproductive seasonality in tropical satyrine butterflies: strategies for the dry season. Ecol. Entomol. 20: 5-17.

Brodeur J. \& Vet L.E.M. 1995: Relationships between parasitoid host range and host defence: a comparative study of egg encapsulation in two related parasitoid species. Physiol. Entomol. 20: 7-12.

Brodeur J., Geervliet J.B.F. \& Vet L.E.M. 1996: The role of host species, age and defensive behaviour on ovipositional decisions in a solitary specialist and a gregarious generalist parasitoid (Cotesia species). Entomol. Exp. Appl. 81: 125-132.

Brodeur J., Geervliet J.B.F. \& Vet L.E.M. 1998: Effects of Pieris host species on life history parameters in a solitary specialist and gregarious generalist parasitoid (Cotesia species). Entomol. Exp. Appl. 86: 154-152.

Danilevski A.S. 1965: Photoperiodism and Seasonal Development of Insects. Oliver \& Boyd, London, $283 \mathrm{pp}$.

DEMPSTER J.P. 1984: The natural enemies of butterflies. In VaneWright R.I. \& Ackery P.R. (eds): The Biology of Butterflies. Symp. R. Entomol. Soc. London, Vol. 11, Academic Press, London, pp. 97-104.

Feltwell J. 1982: Large White Butterfly: the Biology, Biochemistry and Physiology of Pieris Brassicae (Linnaeus). Junk, The Hague, 535 pp.

GeIspits K.F. \& KYAo I.I. 1953: The influence of the length of illumination on the development of certain braconids (Hymenoptera). Entomol. Obozr. 33: 32-35. (In Russian)

Gómez-Bustillo M.R. \& Fernandez-Rubido F. 1974: Mariposas de la Peninsula Ibérica, I/II: Ropalóceros. Servicio de Publicaciones de Ministerio de Agricultura, Madrid, $258 \mathrm{pp}$.

Gom T. 1997: Slow pupal development induced by larval temperature in the fall webworm Hyphantria cunea Drury (Lepidoptera: Arctiidae): Implication for interpopulation variation in incidence. Appl. Entomol. Zool. 32: 517-521.

GRÜNER C. \& MASAKI S. 1994: Summer diapause in the polymorphic life cycle of the noctuid moth Mamestra brassicae. In Danks V.H. (ed.): Insect Life Cycle Polymorphism: Theory, Evolution, and Ecological Consequences for Seasonality and Diapause Control. Kluwer Academic Publishers, Dordrecht, pp. 191-204.

GRÜNER C. \& SAUER K.P. 1988: Aestival dormancy in the cabbage moth Mamestra brassicae L. 1. Adaptive significance of the variability of two traits: Day length thresholds triggering aestival dormancy and duration of aestival dormancy. Oecologia (Heidelb) 74: 515-523.

Hamilton A.G. 1936: Miscellaneous observations on the biology of Apanteles glomeratus (Braconidae). Entomol. Mon. Mag. 72: 24-27.

Held C. \& Spieth H.R. 1999: First evidence of pupal summer diapause in Pieris brassicae L.: the evolution of local adaptedness. J. Insect Physiol. 45: 578-598.

JAMDA N. 1991: On the migration of the large cabbage white butterfly Pieris brassicae in Kashmir. J. Bombay Nat. Hist. Soc. 88: 297-298.

Košř́l V. \& Hodek I. 1997: Photoperiodism and control of summer diapause in the Mediterranean tiger moth Cymbalophora pudica. J. Insect Physiol. 43: 767-777.

LAING J.E. \& LEVIN D.B. 1982: A review of the biology and a bibliography of Apanteles glomeratus (L.) (Hymenoptera: Braconidae). Biocontrol News Information 3: 7-23.

Lien-Chang L. 1965: Studies on the apple pierid (Aporia crataegi L.) in Shansi. Acta Entomol. Sin. 14: 545-551.

MASAKI S. 1961: Geographic variation of diapause in insects. Bull. Fac. Agric. Hirosaki Univ. 7: 66-98.

Masaki S. 1980: Summer diapause. Annu. Rev. Entomol. 25: $1-25$.

Masetti M. \& SCALI V. 1972: Ecological adjustments of the reproductive biology of Maniola jurtina from Tuscany. Atti. Accad. Naz. Lincei Rend. 53: 460-470.

MaslenniKova V.A. 1958: The conditions determining diapause in the parasitic Hymenopteron Apanteles glomeratus L. (Hymenoptera, Braconidae) and Pteromalus puparum (Hymenoptera, Chalcididae). Entomol. Rev. 37: 466-472. 
MaslenniKova V.A. 1959: The relationship of the seasonal development of Apanteles glomeratus $\mathrm{L}$. to that of its host Pieris brassicae L. in different geographical populations. Entomol. Rev. 38: 463-467.

Masurier Le A.D. 1991: Effect of host size on clutch size in Cotesia glomerata. J. Anim. Ecol. 60: 107-118.

Medvedev G.S. 1995: Keys to the Insects of the European Part of the USSR, Vol. III, Part IV: Braconidae. Oxonian Press, New Delhi, $885 \mathrm{pp}$.

MorseEva T.S. 1960: Specialization of Apanteles glomeratus L. and its role in the reduction of the numbers of Pieris spp.. Tr. Vses. Inst. Zash. Rast. 14: 51-56.

MüLler M.J. 1983: Handbuch Ausgewählter Klimastationen der Erde, 3rd ed. Forschungsstelle Bodenerosion der Universität Trier Mertesdorf, Trier, $346 \mathrm{pp}$.

NAGASAKA K. 1992: Why does only Athalia japonica enter summer diapause among three sympatric Athalia sawflies feeding on crucifers? Res. Popul. Ecol. 34: 383-395.

NAKAI T. \& TAKEDA M. 1995: Temperature and photoperiodic regulation of summer diapause and reproduction in Pyrrhalta humeralis (Coleoptera: Chrysomelidae). Appl. Entomol. Zool. 30: 295-301.

NIXON G.E. 1974: A revision of the north-western European species of the glomeratus-group of Apanteles Förster (Hymenoptera, Braconidae). Bull. Entomol. Res. 64: 453-524.

NyLin S., Wickman P.O. \& WikLund CH. 1989: Seasonal plasticity in growth and development of the speckled wood butterfly, Pararge aegeria (Satyridae). Biol. J. Linn. Soc. 38 155-171.

OKU T. 1983: Aestivation and migration in noctuid moths. In Brown V.K. \& Hodek I. (eds): Diapause and Life Cycle Strategies in Insects. Junk, The Hague, pp. 219-231.

RichARDS O.W. 1940: The biology of the small white butterfly, Pieris rapae L., with special reference to the factors controlling its abundance. J. Anim. Ecol. 9: 243-288.
SAто Y. 1980: Experimental studies on parasitization by Apanteles glomeratus: 5 . Relationship between growth rate of parasitoid and host age at the time of oviposition. Entomophaga 25: $123-128$

Sato Y. \& Ohsakr N. 1987: Host-habitat location by Apanteles glomeratus and effect of food-plant exposure on hostparasitism. Ecol. Entomol. 12: 291-297.

SPIETH H. 1985: Die Anpassungen des Entwicklungszyklus an unterschiedlich lange Vegetationsperioden beim Wanderfalter Pieris brassicae L. (Lepidoptera: Pieridae). Zool. Jahrb. Syst. 112: $35-69$.

TAKEDA M. 1997: Effects of photoperiod and temperature on larval development and summer diapause in two geographic ecotypes of the rice stem maggot, Chlorops oryzae Matsumura (Diptera: Chloropidae). Appl. Entomol. Zool. 32: 63-74.

Walter H. \& Lieth H. 1960: Klimadiagramm Weltatlas. Fischer, Jena, $130 \mathrm{pp}$.

Wiklund CH., Persson A. \& Wickman P.O. 1983: Larval aestivation and direct development as alternative strategies in the speckled wood butterfly, Pararge aegeria, in Sweden. Ecol. Entomol. 8: 233-238.

Wilbert H. 1959: Apanteles glomeratus (L.) als Parasit von Aporia crataegi (L.) (Hymenoptera: Braconidae). Beitr. Entomol. 9: 874-898.

Williams C.B. 1958: Insect Migration. Collins, London, 235 pp.

WisKeRKE J.S.C. \& Vet L.E.M. 1994: Foraging for solitarily and gregariously feeding caterpillars: a comparison of two related parasitoid species (Hymenoptera: Braconidae). J. Insect Behav. 7: 585-603.

Xue F., Kallenborn H.G. \& Wer H. 1997: Summer and winter diapause in pupae of the cabbage butterfly, Pieris melete Ménétriés. J. Insect Physiol. 43: 701-707.

Received April 10, 2000; revised October 17, 2000; accepted April 2, 2001 